Review Article

\title{
The Role of Technology in High-tech Agricultural Development in the Context of Social, Ecological and Economic Transformation in Vietnam
}

\author{
Nguyen Thi Ngoc Anh* \\ VNU University of Social Sciences and Humanities, Vietnam National University, Hanoi, \\ 336 Nguyen Trai, Thanh Xuan, Hanoi, Vietnam
}

Received 24 March 2020

Revised 21 March 2020; Accepted 24 March 2020

\begin{abstract}
The world has come to the point that requires more agricultural production using less resource. Moreover, the previous important elements for agricultural growth such as water, land, and human resources no longer play the decisive roles in the agricultural development. Instead, the application of high technology is the "key solution" for countries that depend on the agricultural economy like Vietnam. In Vietnam, agriculture is a particular economic sector that uses the majority of natural and human resources of the country. In the context of the social, ecological and economic transformation, the development of high-tech agriculture is not only about economic efficiency but also the issues of sustainable environmental development. High technology will be the solution to this multi-objective problem. The paper focuses on assessing the necessity of hightech agricultural development and analyzing the role of technology in high-tech agricultural development, especially in the context that contains many challenges and opportunities.
\end{abstract}

Keywords: Technology, high-tech agriculture, Vietnam's agriculture.

\footnotetext{
* Corresponding author.

E-mail address: nguyenngocanh.ipam@gmail.com

https://doi.org/10.25073/2588-1116/vnupam.4213
} 


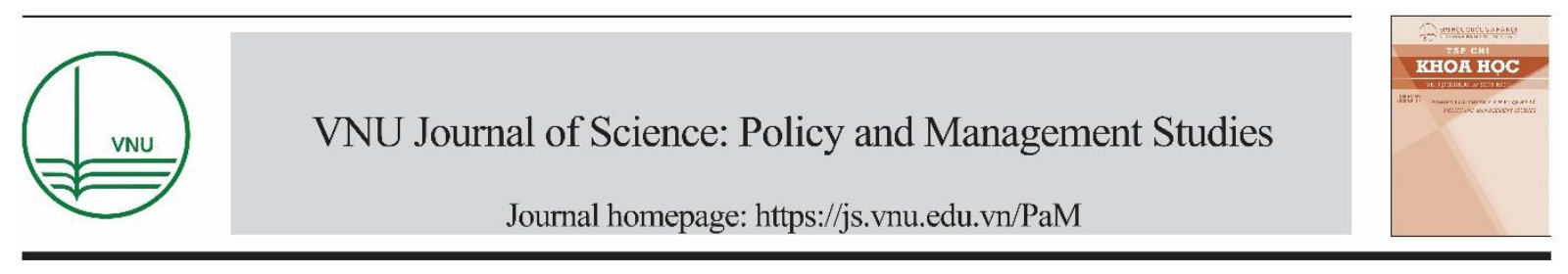

\title{
Vai trò của công nghệ đối với phát triển nông nghiệp công nghệ cao trong bối cảnh chuyển đổi kinh tế, sinh thái và xã hội tại Việt Nam hiện nay
}

\author{
Nguyễn Thị Ngọc Anh \\ Truờng Đại học Khoa học Xã hội và Nhân văn, Đại học Quốc gia Hà Nội \\ 336 Nguyễn Trãi, Thanh Xuân, Hà Nộ \\ Nhận ngày 24 tháng 2 năm 2020 \\ Chỉnh sửa ngày 21 tháng 3 năm 2020; Chấp nhận đăng ngày 24 tháng 3 năm 2020
}

\begin{abstract}
Tóm tắt: Thế giới đã và đang tiến đến giai đoạn yêu cầu phải sản xuất nông sản nhiều hơn với nguồn tài nguyên ít hơn. Hơn nữa, các yểu tố giúp nông nghiệp tăng trưởng như tài nguyên nước, đất đai, nguồn nhân công không còn tác dụng quyết định cho sự phát triển của ngành nữa mà việc ứng dụng công nghệ cao mới là "cứu cánh" đối với các quốc gia mà nền kinh tế đang phụ thuộc nông nghiệp như Việt Nam. Đối với Việt Nam, trong các ngành kinh tế thì nông nghiệp là ngành kinh tế đặc thù, sử dụng phần lớn các tài nguyên thiên nhiên và lực lượng lao động của cả nước. Trong bối cảnh chuyển đổi kinh tế, sinh thái và xã hội hiện nay thì phát triển nông nghiệp công nghệ cao không đơn thuần chỉ là tính đến hiệu quả kinh tế mà còn phải tính đến các vấn đề phát triển môi trường bền vững. Công nghệ cao sẽ là lời giải cho bài toán nhiều mục tiêu này. Bài viết tập trung chính vào đánh giá sự cần thiết của việc phát triển nông nghiệp công nghệ cao và khẳng định vai trò của công nghệ trong phát triển nông nghiệp công nghệ cao trong bối cảnh trong nước và quốc tế chứa đựng nhiều thách thức cũng như cơ hội như hiện nay.
\end{abstract}

Tù̀ khóa: Công nghệ, nông nghiệp Việt Nam, nông nghiệp công nghệ cao.

\section{Dẫn nhập}

Chúng ta đang sống ở một thế giới với những đợt sóng thay đổi lớn lao về xã hội, kinh tế và đặc biệt là công nghệ. Cuộc cách mạng công nghiệp 4.0 với nền tảng công nghệ đã ăn

\footnotetext{
*Tác giả liên hệ.

Địa chỉ email: nguyenngocanh.ipam@gmail.com
}

https://doi.org/10.25073/2588-1116/vnupam.4213 sâu, tạo nên những sự biến đổi về phương thức hoạt động, sản xuất và quản lý trên tất cả lĩnh vực, trong đó có nông nghiệp. Đối với các quốc gia phát triển khác thì việc công nghiệp hóa, hiện đại hóa trong nông nghiệp đã là câu chuyện từ thế kỷ trước, nhưng với một đất nước đang phát triển như Việt Nam thì câu chuyện áp dụng công nghệ vào lĩnh vực nông nghiệp vẫn là một câu hỏi lớn và là một bài toán khó đối với các cơ quan quản lý nhà nước, doanh 
nghiệp và người nông dân hiện nay. Trong bối cảnh chuyển đổi kinh tế, sinh thái xã hội với nhiều cơ hội và rào cản hiện nay, nền nông nghiệp công nghệ cao Việt Nam ở tương lai gần hay còn xa vời phụ thuộc rất nhiều yếu tố, trong đó cốt lõi là yếu tố công nghệ và các chính sách liên quan. Sự cần thiết phải phát triển nền nông nghiệp công nghệ cao và bài học kinh nghiệm của nhiều quốc gia đã được bàn đến nhiều và mở ra nhiều chiều hướng phát triển cho nền nông nghiệp Việt Nam. Tuy nhiên, việc phân tích sâu hơn về quá trình hình thành công nghệ và sợi dây kết nối với sản xuất nông nghiệp còn chưa được đề cập nhiều. Bài viết này tác giả muốn đề cập tập trung vào vai trò của công nghệ trong việc phát triển nền nông nghiệp công nghệ cao trong bối cảnh gắn kêt $R \& D$ và sản xuất và gắn với các diễn tiến chuyển đổi kinh tế, sinh thái và xã hội tại Việt Nam hiện nay.

\section{Một vài vấn đề lý luận về nông nghiệp công nghệ cao}

Ở các công trình nghiên cứu nước ngoài, khái niệm NNCNC (hi-tech agriculture) rất ít xuất hiện thay vào đó, được nhắc nhiều hơn với trang trại công nghệ cao (hi-tech farm), nông nghiệp 4.0 (agriculture 4.0), trang trại thông minh (smart farming), nông nghiệp điện tử (eagriculture),...Do vậy, khi nhắc đến $\mathrm{NNCNC}$, theo nghiên cứu của tác giả thì chỉ dừng lại với một vài định nghĩa mang tính hạn hẹp.Theo Ngân hàng Quốc gia cho Nông nghiệp và Phát triển nông thôn Ấn Độ (NABARD) [1] thì nông nghiệp công nghệ cao (NNCNC) "chủ yếu đề cập đến các hoạt động nông nghiệp liên quan đến các công nghệ mới nhất. Đây là một nền nông nghiệp thâm dụng vốn vì cần phải có vốn lớn để mua thiết bị chuyên dụng, bảo trì tài sản, đào tạo lao động, ... Nông nghiệp công nghệ cao chủ yếu liên quan đến hệ thống canh tác thương mại nhằm phục vụ theo nhu cầu của cả thị trường trong nước cũng như xuất khẩu. Nó sử dụng công nghệ canh tác để tăng năng suất, đảm bảo chất lượng cao (thường không có thuốc trừ sâu) và tăng giá trị thị trường”. Cùng quan điểm với nghiên cứu trên, trong một hội thảo tổ chức năm 2018 tại Bangladesh, tác giả Sachin Tyagi [2] đã đưa ra khái niệm "NNCNC là sự thích ứng của các kỹ thuật mới nhất và tiên tiến, như các phương pháp nâng cao năng suất, công nghệ cao và phát triển nhanh nhất, trồng cây trong điều kiện chính xác của nhiệt độ và độ ẩm, thúc đẩy độ phì nhiêu của đất và dinh dưỡng cây trồng cân bằng, quản lý hữu cơ, tăng thêm giá trị và quản lý sau thu hoạch,... NNCNC cũng có thể bảo vệ môi trường thông qua việc giảm sử dụng hóa chất nông nghiệp". Hai định nghĩa về NNCNC này tập trung vào mảng nông nghiệp trồng trọt và nhấn mạnh đến vai trò của công nghệ như là yếu tố nền, cốt lõi để tạo ra các giá trị về kinh tế và quản lý nông nghiệp

Ở Việt Nam, theo Bộ Nông nghiệp và Phát triển Nông thôn Việt Nam [3] thì "NNCNC là một nền nông nghiệp có sửdụng công nghệ thông tin, công nghệ sinh học, công nghệ vật liệu mới, công nghệ tự động hóa, công nghệ sau thu hoạch và công nghệ quản lý nhằm tăng năng suất, chất lượng, hiệu quả và sức cạnh tranh cao của nông sản hàng hóa, đảm bảo phát triển bền vững". Trong nghiên cứu về "Mối liên kết ba với việc ứng dụng công nghệ cao trong nông nghiệp theo nhu cầu thị trường", tác giả Dương Hữu Bường [4] đã đưa ra định nghĩa về "NNCNC là nền nông nghiệp ứng dụng kết quả nghiên cứu và triển khai $(R \& D)$ có hàm lượng khoa học và công nghệ cao, tạo ra hàng hóa/dịch vụ nông nghiệp có chất lượng và năng suất cao, có giá trị kinh tế cao, thân thiện với môi trường". Trong khái niệm này, tác giả nhấn mạnh đến việc cân bằng giữa đầu vào "sản phẩm $R \& D$ có hàm lượng khoa học và công nghệ cao" và đầu ra là các giá trị về kinh tế, môi trường. Tiếp đó, Dương Hoa Xô, Phạm Hữu Nhượng [5] đã dẫn giải khái niệm của Vụ Khoa học Công nghệ và Môi trường, Bộ Nông nghiệp và Phát triển Nông thôn: "NNCNC là nền nông nghiệp được áp dụng những công 
nghệ mới vào sản xuất bao gồm: công nghiệp hóa nông nghiệp (cơ giới hóa các khâu của quá trình sản xuất), tự động hóa, công nghệ thông tin, công nghệ vật liệu mới, công nghệ sinh học và giống cây trồng, giống vật nuôi có năng suất và chất lượng cao, đạt hiệu quả kinh tế cao trên một đơn vị diện tích và phát triển bền vững trên cơ sở canh tác hữu cơ”. Đến khái niệm này, tác giả ngoài việc nhấn mạnh đến công nghệ chủ chốt trong NNCNC thì còn đề cập đến hiệu quả về kinh tế và sinh thái.

Qua nghiên cứu của Dương Anh Đào [6] thì NNCNC có một số đặc trưng sau:

- Mô hình NNCNC được triển khai trên cơ sở kết hợp giữa "hạt nhân công nghệ cao" - là các khu NNCNC và sản xuất đại trà

- NNCNC ảnh hưởng đến sự tiêu chuẩn hóa và đa dạng hóa ở mức cao các loại sản phẩm, đáp ứng ngày càng tốt hơn và đầy đủ hơn cho nhu cầu thị trường

- NNCNC phải kết hợp chặt chẽ với du lịch sinh thái và du lịch tri thức và phát triển phải dựa trên quan điểm phát triển bền vững

- NNCNC cần có sự liên kết chặt chẽ giữa 4 nhà là Nhà nước - Nhà khoa học - Nhà nông và Doanh nghiệp

Như vậy, có thể thấy, bản thân trong khái niệm NNCNC đã bao hàm và khẳng định vai trò của nông nghiệp công nghệ cao. Nông nghiệp công nghệ cao không chỉ là thành tựu của khoa học và công nghệ, không còn là "sân chơi” riêng của người nông dân mà nó còn có vai trò đặc biệt đối với sự phát triển kinh tế - xã hội ở cả tầm vi mô và vĩ mô. Có thể khái quát một số vai trò chính của NNCNC như sau:

- Úng phó với việc khan hiếm tài nguyên: Hiện nay, khi các tài nguyên ngày càng trở nên hạn hẹp mà nông nghiệp lại là một đối tượng chịu tác động nhiều bởi đầu vào là nguồn tài nguyên (đất, nước,...). Hơn nữa, nhu cầu của con người ngày càng cao cả về số lượng và chất lượng nên NNCNC là một giải pháp "cứu cánh" cho cả hai tình trạng trên.
- Thích ứng với biến đổi khí hậu: Với quá trình sản xuất và sinh hoạt của con người, khí hậu chịu tác động lớn và ngày càng xuất hiện nhiều hiện tượng tiêu cực., Những hậu quả gây ra từ những biến đổi khí hậu trên vô cùng nặng nề, tác động trực tiếp đến đầu vào, đầu ra và cả quá trình sản xuất nông nghiệp. NNCNC giúp giảm thiểu và thích ứng với biến đổi khí hậu như hạn chế rác thải nông nghiệp, sản xuất nông nghiệp trong điều kiện khan hiếm về nguồn nước, nước ngập mặn,...

- Giảm công sức lao động và tăng giá trị sản phẩm: Với việc ứng dụng khoa học và công nghệ cao giúp người sản xuất nông nghiệp giảm công sức lao động thông qua các hệ thống tự động hóa, cơ giới hóa. Thêm vào đó, trình độ lao động được nâng cao thông qua quá trình học hỏi và sáng tạo, góp phần chuyển dịch cơ cấu lao động. Đồng thời, ứng dụng công nghệ cao giúp tăng năng suất, chất lượng, giảm giá thành sản phẩm và giảm tối đa thiệt hại trong sản xuất nông nghiệp. Từ đó, nguồn thu từ nông nghiệp đem lại giá trị cho người sản xuất.

- Đẩy nhanh quá trình công nghiệp hóa và hiện đại hóa nền kinh tế quốc gia: Trong bối cảnh cuộc Cách mạng công nghiệp 4.0 với nhiều biến đổi về công nghệ, gây ra nhiều tác động đến kinh tế-xã hội và buộc mọi hoạt động đều phải có sự thay đồi thích ứng. Nông nghiệp cũng không nằm ngoài sự tất yếu đó.

- Huy động nguồn lực trong phát triển nông nghiệp: Nông nghiệp luôn là một trong ba trụ cột trong sự phát triển kinh tế của một quốc gia, thậm chí còn là ngành trụ cột đối với nhiều quốc gia như Việt Nam. Việc chuyển đổi sang mô hình NNCNC giúp gắn kết các nguồn lực về nhân lực, tài chính, cơ sở vật chất cho phát triển nông nghiệp thay vì coi đó là công việc riêng của những người nông dân như trước kia. Việc liên kết hai "nhà", ba "nhà", bốn "nhà", năm "nhà" đã trở thành những liên kết cơ hữu để tạo dựng một hệ sinh thái nông nghiệp phát triển bền vững. 
Dựa trên các tiêu chí đánh giá ứng dụng công nghệ cao trong các chính sách liên quan, Dương Anh Đào [7] cũng đưa ra các nhóm tiêu chí đánh giá nền nông nghiệp công nghệ cao như sau:

Nhóm tiêu chí về khoa học và công nghệ:

+ Có trình độ công nghệ tiên tiến tạo ra sản phẩm có năng suất tăng ít nhất $30 \%$ và chất lượng vượt trội so với công nghệ đang sử dụng.

+ Công nghệ phải liên tục nghiên cứu đổi mới phù hợp với sự phát triển của khoa học và công nghệ, có thể ứng dụng và mở rộng trong những điều kiện sinh thái nông nghiệp nhất định.

+ Công nghệ phải là tiên tiến tại thời điểm đầu tư.

+ Công nghệ phải mang lại hiệu quả kinh tế cao, sản phẩm NNCNC phải đáp ứng được các yêu cầu về chất lượng của quốc gia và quốc tế như VietGAP, AseanGAP, EuropGAP, GlobalGAP,...

Nhóm các tiêu chí về kinh tế, xã hộ và môi truờng

+ Về kinh tế: Sản phẩm của nền NNCNC phải có hiệu quả kinh tế cao hơn ít nhất $30 \%$ so với sản phẩm của nền nông nghiệp truyền thống.

+ Về xã hội: Sản phẩm được sản xuất ra từ nền $\mathrm{NNCNC}$ phải đáp ứng được yêu cầu và thị hiếu của người tiêu dùng về số lượng và chất lượng; việc ứng dụng công nghệ cao vào sản xuất nông nghiệp phải thay đổi được các tập quán vốn có như tập quán canh tác sản xuất, tập quán mua bán hàng hóa nông sản, tập quán tiêu dùng;... hướng đến một nền sản xuất nông nghiệp hiện đại, theo phương thức sản xuất tập trung; đảm bảo thu nhập và ổn định chất lượng cuộc sống người dân. Đồng thời, về mặt tổ chức quản lý, Nhà nước phải ban hành các chính sách liên quan đến việc ứng dụng cộng nghệ cao trong nông nghiệp như luật, tiêu chuẩn chất lượng sản phẩm,...

+ Về môi trường: đảm bảo hạn chế thải ra các chất gây ô nhiễm môi trường, không vượt quá giới hạn cho phép; không làm tổn hại đến môi trường sinh thái nơi sản xuất và các hệ sinh thái xung quanh.

Nhóm tiêu chí về sản phẩm nông nghiệp công nghệ cao:

Sản phẩm của nền NNCNC trước hết phải đáp ứng các yêu cầu: có tỷ trọng giá trị gia tăng cao trong cơ cấu tổng giá trị sản phẩm; có tính cạnh tranh cao và hiệu quả kinh tế - xã hội lớn; có khả năng xuất khẩu hoặc thay thế sản phẩm nhập khẩu; góp phần nâng cao năng lực khoa học và công nghệ quốc gia. Thêm vào đó, sản phẩm phải hấp dẫn về hình thức, đảm bảo về chất lượng, môi trường sản xuất, thu hoạch, chế biến đúng quy định, đảm bảo các quy định liên quan về người lao động,...

\section{Mối quan hệ giữa phát triển nông nghiệp công nghệ cao và bối cảnh chuyển đổi kinh tế, sinh thái và xã hội}

Theo Nhóm Ngân hàng Thế giới [8], Việt Nam cũng như các quốc gia khác đang phải trải qua một loạt các chuyển đổi trước sức ép về nhân khẩu, kinh tế, thị trường và các yếu tố khác. Trong quá trình chuyển đổi đó, ba trụ cột là kinh tế - sinh thái - xã hội có nhiều biến động liên quan đến nông nghiệp. Và nông nghiệp công nghệ cao có tác động qua lại với kinh tế, sinh thái và xã hội. Có thể khái quát như sau:

Về kinh tế: Trong khu vực Đông Á và Đông Nam Á, tổng mức tiêu thụ lương thực thực phẩm dự kiến sẽ tăng và đa dạng hóa nhanh chóng do dân số, kinh tế, thu nhập và mức độ đô thị hóa đều tăng [8]. Thay đổi tiêu dùng thay đổi như trên sẽ có tác động kinh tế rất lớn. Và điều này có tác động mạnh mẽ đến nền kinh tế Việt Nam bởi ngoài là một nước với cơ cấu nông nghiệp chiếm tỷ trọng cao thì Việt Nam là một trong những nước top đầu về xuất khẩu nông sản. Những thay đổi về mô hình sản xuất nông nghiệp sẽ dẫn đến những thay đổi về hành vi tiêu dùng, hành vi sản xuất, giá trị sản xuất, thị trường và các chuỗi giá trị. 
Về xã hội: Nông nghiệp công nghệ cao thay đổi tư duy về sản xuất nông nghiệp, thay đổi cơ cấu lao động nông nghiệp và biến "nông dân" trở thành một nghề. Thêm vào đó, nông nghiệp công nghệ cao tác động nhiều đến các mối quan hệ trong sản xuất nông nghiệp, thay đổi hành vi tiêu dùng. Với nông nghiệp truyền thống thì đơn thuần sản xuất, tiêu thụ là việc của người sản xuất. Nhưng với nông nghiệp công nghệ cao thì mối quan hệ trong sản xuất được tham gia bởi rất nhiều đối tượng và tạo thành chuỗi giá trị. Kèm với đó, sản xuất nông nghiệp trong bối cảnh chuyển đổi xã hội cũng kéo theo các yêu cầu về tiêu chuẩn hàng hóa chất lượng, truy xuất nguồn gốc.

Về sinh thái: Theo như dự đoán của Nhóm Ngân hàng Thế giới [8] thì trong tương lai biến đổi khí hậu tại Việt Nam sẽ là yếu tố nổi bật thúc đẩy chuyển đổi nông nghiệp cũng như các thay đổi khác về địa lý, tự nhiên và chất lượng sản xuất. Nông nghiệp công nghệ cao sẽ một phần hạn chế những tác động tiêu cực từ nông nghiệp đến sinh thái, môi trường, hạn chế biến đổi khí hậu, một phần là thích ứng sản xuất nông nghiệp trong bối cảnh biến đổi về sinh thái môi trường đó. Kèm với đó, những xu hướng mới như nông nghiệp kết hợp du lịch sinh thái, nông nghiệp xanh, nông nghiệp thân thiện môi trường,...đã góp phần đem lại giá trị đối với hệ sinh thái.

Ngay như Mục 1 đã phân tích thì nhóm tiêu chí về kinh tế, xã hội, môi trường cũng được đề cao và trở thành một trong ba yếu tố tiên quyết

Bảng 1. Số lượng và cơ cấu lao động từ 15 tuổi trở lên có việc làm chia theo khu vực kinh tế [11] để hình thành, đánh giá và xây dựng nền NNCNC. Như vậy, nông nghiệp công nghệ cao có ảnh hưởng lớn đến kinh tế - xã hội - sinh thái và ngược lại ba yếu tố này cũng có tác động mạnh mẽ đến sự phát triển và thay đổi của mô hình nông nghiệp mới: nông nghiệp công nghệ cao.

\section{Sự cần thiết phát triển nông nghiệp công nghệ cao trong bối cảnh chuyển đổi kinh tế, sinh thái, xã hội tại Việt Nam hiện nay}

Thư nhất, có nhiều "yếu điểm" trong phát triển nông nghiệp của Việt Nam hiện nay. Đối với Việt Nam, đặc trưng lịch sử và phát triển văn hóa gắn liền với cụm từ "nền văn minh lúa nước" và có tới $70 \%$ lực lượng lao động đang làm việc trong khu vực nông nghiệp. Là một đất nước với lợi thế về phát triển nông nghiệp nhưng những con số mà chúng ta thấy lại không chứng minh điều đó. Theo số liệu tính toán của Tổng cục Thống kê, trong tháng 1/2019, cả nước có gần 5,7 nghìn hộ thiếu đói, tương ứng với 19,6 nghìn nhân khẩu thiếu đói [9]; nông nghiệp chỉ đóng góp khoảng $20 \%$ GDP, số lao động tham gia ngành nông nghiệp ngày càng giảm (xem Bảng 1), trình độ công nghệ trong nông nghiệp đang ở giai đoạn giữa nền nông nghiệp 1.0 và nền nông nghiệp 2.0 [10]; các yếu tố rủi ro như rét đậm, rét hại, mưa lớn và sạt lở đất tại một số địa phương làm hàng nghìn ha lúa và hoa màu bị ngập, hư hỏng; những thẻ vàng trong xuất khẩu thủy sản,...

\begin{tabular}{lllll}
\hline & Tổng số & \multicolumn{3}{c}{ Chia ra } \\
\cline { 3 - 5 } & & $\begin{array}{l}\text { Nông, lâm } \\
\text { nghiệp, thuỷ sản }\end{array}$ & $\begin{array}{l}\text { Công nghiệp và } \\
\text { xây dụng }\end{array}$ & Dịch vụ \\
\hline Số lượng (nghìn người) & & & & \\
\hline Năm 2018 & & & & \\
Quý I năm 2018 & 53992,8 & 20821,6 & 14355,0 & 18816,2 \\
Quý II năm 2018 & 54 022,8 & 20642,5 & 14382,5 & 18997,8 \\
Quý III năm 2018 & 54300,9 & 20550,3 & 14405,0 & 19345,6 \\
\hline Quý IV năm 2018 $\left(^{*}\right)$ & 54530,3 & 19922,0 & 15136,5 & 19471,8 \\
\hline
\end{tabular}




\begin{tabular}{lllll}
\hline $\begin{array}{l}\text { Năm 2019 } \\
\text { Quý I năm 2019 (*) }\end{array}$ & 54322,0 & 19244,7 & 15553,5 & 19523,8 \\
\hline Có cấu (\%) & & & & \\
\hline Năm 2018 & & 38,6 & 26,6 & 34,8 \\
Quý I năm 2018 & 100,0 & 38,2 & 26,6 & 35,2 \\
Quý II năm 2018 & 100,0 & 37,8 & 26,5 & 35,6 \\
Quý III năm 2018 & 100,0 & 36,5 & 27,8 & 35,7 \\
Quý IV năm 2018 & 100,0 & & & \\
Năm 2019 & & 35,4 & 28,6 & 36,0 \\
Quý I năm 2019 $\left(^{*}\right)$ & 100,0 & & & \\
\hline
\end{tabular}

Những số liệu trên đã chứng minh rằng nông nghiệp mà chúng ta vẫn coi là thế mạnh nhưng thực ra lại chưa thể cung cấp đủ về số lượng và đảm bảo chất lượng nông sản trong chính thị trường nội địa mình. Đây thực sự là một vấn đề nan giải. Nền nông nghiệp Việt Nam đang phải đối mặt với nhiều thách thức lớn từ trong và ngoài từ cuộc chuyển đổi kinh tế, sinh thái và xã hội hiện nay. Cụ thể:

Những thách thức nội tại:

+ Mặc dù Việt Nam được đánh giá là có co cấu dân số trẻ, có nguồn lao động dồi dào nhưng nhân lực làm trong ngành nông nghiệp ngày càng giảm và hầu hết là không có trình độ, sản xuất chủ yếu dựa trên kinh nghiệm. Năng suất lao động trong nông nghiệp không chỉ thấp so với các ngành kinh tế khác trong nước mà còn có xu hướng chuyển dịch dần sang ngành công nghiệp-dịch vụ [12]. Việt Nam còn phải đối mặt với việc suy giảm nhân lực trong ngành này khi mà việc lựa chọn một công việc khác chứ không phải trở thành một người "nông dân" luôn là sự lựa chọn "tất nhiên" của giới trẻ hiện nay.

+ Quỹ đất nông nghiệp tiếp tục suy giảm do công nghiệp hóa và đô thị hóa. Chưa kể đến việc lực lượng nhân lực làm nông nghiệp giảm dẫn đến một lượng lớn đất bị bỏ hoang, không có nhân lực canh tác.

+ Biến đổi khí hậu đã và đang diễn ra cũng ảnh hưởng lớn đến diện tích đất nông nghiệp và nguồn nước ngọt dùng trong sản xuất nông nghiệp. Vấn đề nóng lên toàn cầu và băng tan khiến mực nước biển ngày càng tăng khiến quỹ đất nông nghiệp bị ngập mặn hoặc sa mạc hóa đang diễn ra ngày càng nhiều (Hình 1). Bộ Tài nguyên Môi trường ước lượng rằng đến năm 2030 mực nước biển sẽ dâng thêm $17 \mathrm{~cm}$ so với giai đoạn 1980-1999. Vào năm 2050 mực nước biển có thể tăng thêm $30 \mathrm{~cm}$ trên đường cơ sở và đến năm 2100 sẽ tăng thêm đến $75-100 \mathrm{~cm}$ [8].

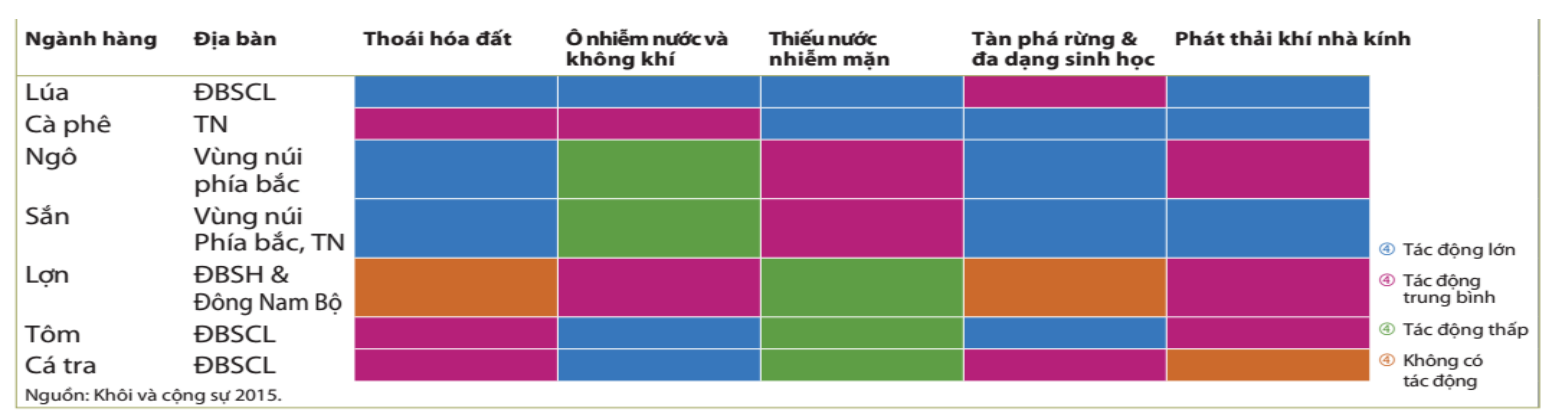

Hình 1. Vấn đề nông nghiệp - môi trường tại một số khu vực ở Việt Nam hiện nay [8] 
+ Giá trị kim ngạch xuất khẩu nông, lâm, thủy sản tăng nhưng chủ yếu là dưới dạng thô. Tình hình năng suất và chất lượng biển động không ngừng, gây khó khăn cho việc sử dụng trong nước cũng như xuất khẩu, hậu quả hàng năm người nông dân phải gánh chịu thua lỗ, rớt giá khi được mùa, trúng vụ và bị ép giá cũng như bị đối tác từ chối, trả lại khi không đáp ứng được các chỉ tiêu, yêu cầu chất lượng xuất khẩu, trong đó có những thị trường rất quan trọng như Hoa Kỳ, EU, Nhật Bản...

Những thách thức từ bên ngoài:

+ Dân số thế giới tăng kéo theo nhu cầu về nông sản thay đổi cả về số lượng và chất lượng. Hơn hết, sự cạnh tranh trong ngành nông nghiệp thế giới đang nóng hơn bao giờ hết.

+ Cuộc cách mạng công nghiệp lần thứ tư đang được lan rộng mạnh mẽ trong lĩnh vực nông nghiệp. Nếu Việt Nam không có sự thay đổi thì sẽ không chỉ đánh mất vị trí hiện tại mà còn phải đối mặt với nguy cơ tụt hậu trên thị trường nông sản thế giới.

Thư hai, phát triển nông nghiệp công nghệ cao là xu thế tất yếu và bắt buộc trong bối cảnh hiện nay. Đối với Việt Nam, trong bối cảnh chuyển đổi kinh tế, sinh thái và xã hội hiện nay còn đang chưa có định hướng rõ ràng, mới tập trung vào các điểm nóng để phát triển kinh tế và chưa chú trọng nhiều đến các yếu tố về môi trường, sinh thái thì cần những mô hình phát triển mang tính bền vững hơn.

Thú $b a$, tiềm năng phát triển nông nghiệp công nghệ cao của Việt Nam hiện nay. Đến năm 2018, Thủ tướng Chính phủ đã quy hoạch 22 Khu Nông nghiệp công nghệ cao; Bộ Nông nghiệp và Phát triển Nông thôn đã công nhận 35 doanh nghiệp nông nghiệp ứng dụng công nghệ cao và các địa phương công nhận 03 Vùng Nông nghiệp ứng dụng công nghệ cao được địa phương công nhận. Các chính sách hỗ trợ về khoa học và công nghệ là những động lực đặc biệt quan trọng trong tăng trưởng nông nghiệp; các tiến bộ khoa học và công nghệ đã đóng góp khoảng 30-40\% vào tăng trưởng nông nghiệp [13]. Số doanh nghiệp hoạt động trong lĩnh vực nông lâm thủy sản đã tăng từ 3.517 doanh nghiệp năm 2012 lên 4.500 doanh nghiệp năm 2016 và 5.661 doanh nghiệp năm 2017 [14]. Thêm vào đó, phong trào khởi nghiệp trong lĩnh vực nông nghiệp ngày càng nhận được sự quan tâm của giới trẻ và các tập đoàn lớn. Có rất nhiều doanh nghiệp hiện đang đầu tư và phát triển về nông nghiệp công nghệ cao như Công ty TNHH Đầu tư Phát triển Sản xuất Nông Nghiệp VinEco (thuộc Tập đoàn Vingroup), Tập đoàn $\mathrm{TH}$, Công ty $\mathrm{CP}$ Việt Úc,.... Đây là tiền đề cho việc hình thành các doanh nghiệp nông nghiệp công nghệ cao.

Thư tư, chính sách phát triển kinh tế - xã hội đều đang hướng đến phát triển nông nghiệp công nghệ cao. Phát triển nông nghiệp Việt Nam là một trong những định hướng ưu tiên được thể hiện trong nhiều chính sách, chủ trương của Đảng và Nhà nước như: Luật Công nghệ cao 2008; Quyết định số 176/QĐ-TTg của Thủ tướng chính phủ ngày 29/01/2010 về việc phê duyệt đề án phát triển nông nghiệp ứng dụng công nghệ cao đến năm 2020; Nghị định 55/2015/NĐ- CP của Chính phủ về cho vay ưu đãi với nông nghiệp nông thôn; Đề án Phát triển Nông nghiệp công nghệ cao của Bộ Nông nghiệp và Phát triển nông thôn, Gói tín dụng 100.000 tỷ cho doanh nghiệp nông nghiệp công nghệ cao, Quyết định số 19/2018/QĐ-TTg của Thủ tướng Chính phủ ngày 19/4/2018 Quy định tiêu chí, thẩm quyền, trình tự, thủ tục công nhận doanh nghiệp nông nghiệp ứng dụng công nghệ cao,....Đây là những tín hiệu đáng mừng mở đường cho sự phát triển của nông nghiệp công nghệ cao trong thời gian tới.

\section{Vai trò của công nghệ trong phát triển nông nghiệp công nghệ cao tại Việt Nam hiện nay}

Những thách thức và vai trò của việc phát triển nông nghiệp công nghệ cao mà tác giả đã trình bày trong phần trước có thể thấy nổi bật nên yếu tố rào cản lớn của Việt Nam đó là yếu 
tố công nghệ. Bản thân trong cụm từ "nông nghiệp công nghệ cao" đã thể hiện mối quan hệ gắn kết giữa hai thành tố là "công nghệ cao" và "nông nghiệp". Như vậy, ta thấy rằng để phát triển nông nghiệp thì yếu tố nền tảng có vai trò quyết định là công nghệ, hay nói chính xác là công nghệ cao. Đây là yếu tố thiếu và yếu trong nền nông nghiệp Việt Nam. Nền nông nghiệp Việt Nam vẫn dựa vào yếu tố "sức lao động" là chính và trông đợi vào các điều kiện về "thiên thời, địa lợi". Yếu tố công nghệ mới dừng lại ở việc cơ giới hóa nông nghiệp với các loại máy móc đơn giản và chưa "thoát ly" được các rủi ro từ thiên nhiên và chưa làm chủ được thị trường nông sản. Sự thay đổi từ quá trình phát triển kinh tế - xã hội và hội nhập kinh tế quốc tế khiến cho nông nghiệp ngày càng trở nên bấp bênh và xảy ra nhiều xung đột với môi trường. Khi mà việc phát triển mô hình nông nghiệp công nghệ cao đòi hỏi sự tổng hòa của các yếu tố: hiệu quả kinh tế và đảm bảo môi trường bền vững thì các yếu tố liên quan đến công nghệ cao được đặt lên hàng đầu.

So sánh về điều kiện tự nhiên để làm nông nghiệp công nghệ cao, chúng ta hơn hẳn Israel, Nhật Bản,...Hai đặc tính cơ bản của những nền nông nghiệp hàng đầu thế giới là áp dụng triệt để công nghệ và chuyên môn hóa cao độ, tuy nhiên, đây cũng là hai điểm yếu nhất của nông nghiệp Việt Nam. Nhưng thực tiễn cho thấy, thành công của nông nghiệp công nghệ cao không chỉ dựa vào vốn, đất, cơ chế, nhân lực mà còn là vấn đề khoa học và công nghệ. Và đây được coi là hạn chế lớn nhất khiến các nhà doanh nghiệp Việt Nam phải phân vân khi đầu tư phát triển nông nghiệp công nghệ cao. Cội nguồn của công nghệ xuất phát từ hoạt động nghiên cứu và triển khai $(R \& D)$. $R \& D$ từ lâu được coi là nguồn đổi mới cần thiết để duy trì tăng trưởng năng suất nông nghiệp trong dài hạn.

Trong làn sóng của cuộc cách mạng công nghiệp lần thứ tư ở Việt Nam, như trên đã phân tích, chúng ta đã có nhiều chính sách để tiếp cận và thúc đẩy ứng dụng công nghệ 4.0.
Nhưng riêng trong ngành nông nghiệp, chưa có văn bản chính sách nào dành riêng để phát triển nông nghiệp công nghệ cao. Tuy nhiên, trong những năm trở lại đây, Chính phủ đã có nhiều chính sách thúc đẩy ứng dụng công nghệ cao trong nông nghiệp. Điển hình là Quyết định số 1895/QĐTTg năm 2012 phê duyệt chương trình phát triển nông nghiệp ứng dụng công nghệ cao thuộc chương trình quốc gia phát triển công nghệ cao đến năm 2020. Quyết định số 575/QĐ-TTg ngày 04/5/2015 "Phê duyệt quy hoạch tổng thể khu và vùng nông nghiệp ứng dụng công nghệ cao đến năm 2020, định hướng đến năm 2030". Một số các khu nông nghiệp công nghệ cao đã được hình thành ở Việt Nam, và xu hướng áp dụng công nghệ cao trong nông nghiệp đang ngày càng phát triển ở Việt Nam, mặc dù quy mô còn nhỏ. Việt Nam có 29 khu nông nghiệp ứng dụng công nghệ cao hoạt động tại 12 tỉnh, thành phố [14]. Trong đó, có một số mô hình sản xuất nông nghiệp công nghệ cao đầu tư có hiệu quả, đem lại lợi nhuận khá cao như Tập đoàn Lộc Trời, Công ty Giống cây trồng Thái Bình, Tập đoàn Vingroup, Công ty Trách nhiệm hữu hạn Đà Lạt GAP (về lĩnh vực trồng trọt, giống cây trồng); Tập đoàn Việt Úc, Công ty Cổ phần Vĩnh Hoàn (trong lĩnh vực thủy sản); Công ty Cổ phần Ba Huân, Tập đoàn TH True Milk và Công ty Vinamilk (lĩnh vực chăn nuôi),.... Đặc biệt, Trung tâm Phát triển Nông lâm nghiệp công nghệ Hải Phòng với công nghệ tưới tiết kiệm và bón phân có kiểm soát qua ống tưới của Israel cho hiệu quả cao gấp nhiều lần so với phương pháp truyền thống.

Như vậy, không còn là lý thuyết hay xuất hiện trong bài học kinh nghiệm mà hiệu quả đem lại từ công nghệ cao là điều hoàn toàn xuất hiện trên thực tiễn. Tuy nhiên, hiện nay vẫn còn nhiều rào cản, thách thức từ vấn đề "công nghệ" trong phát triển nông nghiệp ứng dụng công nghệ cao như: thiếu sự hỗ trợ, tư vấn về khoa học và công nghệ cho người sản xuất, việc áp dụng công nghệ cao trong nông nghiệp còn manh mún, tự phát, trình độ ứng dụng công 
nghệ còn thấp; trong khi đó tỷ trọng lao động nông nghiệp lớn, chất lượng thấp trong khi các công nghệ cao và mới sẽ khiến nhu cầu về lao động trong nông nghiệp giảm đi; chưa có sự đầu tư thích đáng vào nghiên cứu, ứng dụng và chuyển giao công nghệ. Đây là "điểm nghẽn" mà Việt Nam cần tháo gỡ trong thời gian sắp tới để phát triển nông nghiệp công nghệ cao, đáp ứng các mục tiêu phát triển kinh tế, xã hội và sinh thái.

\section{Kết luận}

Tăng trưởng và phát triển nông nghiệp trong thời gian qua ở Việt Nam vẫn chủ yếu dựa trên sử dụng nguồn nhân lực, tài nguyên thiên nhiên và các vật tư đầu vào. Sản lượng đầu ra và thương mại phát triển với tốc độ nhanh, nhưng đi kèm với đó là những thiệt hại về môi trường, trong khi chất lượng sản phẩm không ổn định, năng suất lao động thấp, giá trị gia tăng hạn chế. Do đó, khẩu hiệu nhất quán phải là đạt được Tăng giá trị, giảm đầu vào [8]. Điều đó có nghĩa là ngành nông nghiệp cần tăng lợi ích cho người sản xuất, người tiêu dùng, hệ sinh thái cũng như các lợi ích kinh tế nói chung, trong khi giảm sử dụng sức lao động, đất, nguồn nước, các tài nguyên thiên nhiên khác và các vật tư đầu vào có hại cho môi trường. Để làm được điều đó thì nông nghiệp công nghệ cao cùng những chính sách nông nghiệp bền vững là công cụ hữu hiệu. Các mô hình sản xuất nông nghiệp dựa trên khoa học và công nghệ sẽ là xu hướng phát triển mạnh mẽ trong thời gian tới để cân bằng ba trụ cột "kinh tế - xã hội - sinh thái” trong tiến trình phát triển của Việt Nam.

Để thúc đẩy ứng dụng công nghệ cao trong nông nghiệp trong bối cảnh chuyển đổi kinh tế, sinh thái và xã hội như hiện nay thì cần có sự tham gia, phối hợp của nhiều bên, từ các nhà làm chính sách, các doanh nghiệp, người nông dân/người sản xuất, các chuyên gia công nghệ, nhà nghiên cứu, và các đơn vị liên quan khác. Một số định hướng phát triển hoạt động R\&D và công nghệ này là việc phát triển các vườn ươm doanh nghiệp nông nghiệp công nghệ cao, tổ chức các chương trình đào tạo nâng cao kiến thức và phổ biến công nghệ cho doanh nghiệp và người sản xuất, hỗ trợ xây dựng các nền tảng công nghệ, khuyến khích doanh nghiệp nước ngoài và doanh nghiệp tư nhân trong nước đầu tư vào nông nghiệp công nghệ cao,....

\section{Lời cảm ơn}

Bài viết là sản phẩm nghiên cứu thuộc đề tài "Nghiên cứu thực trạng và đề xuất chính sách, giải pháp nâng cao năng lực đổi mới sáng tạo (innovation) của doanh nghiệp Việt Nam" (Mã số KX.01.25/16-20) thuộc chương trình khoa học và công nghệ trọng điểm cấp quốc gia giai đoạn 2016 - 2020: "Nghiên cứu những vấn đề trọng yếu về khoa học xã hội và nhân văn phục vụ phát triển kinh tế xã hội” - Mã số KX.01/16-20.

\section{Tài liệu tham khảo}

[1] National Bank for Agriculture and Rural Development, High-tech agriculture in India, National paper, PLP 2020-21, https://www.nabard.org/auth/ writereaddata/CareerNotices/2309195507HighTech\%20Agriculture.pdf (accessed 6 March 2020)

[2] Tyagi, Sachin, Hi-tech agriculture: A solution for food security, in Rural Development Academy (RDA), 'Research and Extension for sustainable rural development', Bangladesh, 2018.

[3] Vietnam Ministry of Agriculture and Rural Development, High-tech agriculture Report, CIS, 3 (2017) 5.

[4] Duong Huu Buong, "Triple Helix" with the Application of High-tech in Agriculture According to Market Demand (in Vietnamese), VNU Journal of Science: Policy and Management Studies 35(2) (2019) 64-73.

[5] Duong Hoa Xo, Pham Huu Nhuong, Developing agriculture towards high technology in Vietnam, Agricultural Extension Forum @ Technology 2006, Da Lat, Lam Dong, 2006. 
[6] Duong Anh Dao, Can Tho City has been towards high-tech agriculture (in Vietnamese), Science Journal of Can Tho, 2013, 20-26.

[7] Duong Anh Dao, Research and development of high-tech agriculture in Can Tho City (in Vietnamese), Master's Thesis in Geography, Ho Chi Minh City University of Education, 2012.

[8] World Bank Group, Vietnam Development Report 2016, Transforming Vietnamese Agriculture: Gaining more from less, Hong Duc Publishing House, 2016.

[9] General Statistics Office of Vietnam, Socioeconomic situation in January 2019, 2019. https://www.gso.gov.vn/default.aspx?tabid=621\& ItemID=19066, (accessed 15 May 2019)

[10] European Agriculture Machinery Association, Digital Farming: what does it really mean?, Position Paper, CEMA, 2017.

[11] General Statistics Office of Vietnam, Labor and Employment situation in the first quarter of 2019 , Press

Release,

2019 ,
https://www.gso.gov.vn/Default.aspx?tabid=382\&id mid=\&ItemID=19136， 2019 (accessed 17 May 2019).

[12] Bui Thi Minh Nguyet, Tran Van Hung, The actual situation and solutions for development of Vietnam agriculture sector in the context of international intergration (in Vietnamese), Journal of Forestry Science and Technology 4 (2016) $142-151$.

[13] Ministry of Science and Technology, Report on Situation of application of science and technology, high technology in agricultural enterprises; evaluate policies and solutions to support enterprises to apply science and technology in agriculture (in Vietnamese), National Conference of Promoting Enterprises Investing in Agriculture, Lam Dong, 2018.

[14] Nguyen Thi Minh Phuong (Editor), Sustainable agricultural policies of some countries and recommend policies to Vietnam in the new context (in Vietnamese), National Agency for Science and Technolofy Information, 7/2019. 